\title{
Reformas administrativas nos estados brasileiros: o caso da reforma administrativa do estado do Piauí
}

\author{
Administrative Reforms in Brazilian states: The case of the State of Piaui's Administrative Reform \\ Las reformas administrativas en los estados brasileños: El caso de la Reforma Administrativa del Estado de Piauí
}

\begin{abstract}
Resumo
0 artigo analisa 0 caso da reforma administrativa do estado do Piauí entre 2003 e 2006. Com abordagem histórica e método de narrativa, explica esse processo. As reformas administrativas nos estados brasileiros foram marcadas pela difusão do ideário do novo gerencialismo público, tendo como marca a implementação de instrumentos de gestão importantes, como privatizações, ajustes fiscais, desenvolvimento de carreiras e racionalização dos processos de planejamento e orçamento. Esse processo de difusão de reformas administrativas estaduais ao longo dos anos de 1990 denomina-se conjuntura isomórfica. Um traço comum nas reformas dos estados brasileiros foi o impacto de seus contextos políticos locais nas novas estruturas institucionais. Isso marcou a permeabilidade e resistência de implementação das reformas. Não foi diferente com a reforma administrativa do Piauí, que ocorreu a partir do rearranjo das forças políticas do estado, porém sofrendo as vicissitudes da política local, que terminaram por influenciar decisivamente nos resultados.
\end{abstract}

Palavras-chave: Reforma gerencial, reforma administrativa do Piauí, isomorfismo.

Antônio Sérgio Araújo Fernandes - antoniosaf@ufba.br

Professor Associado da Universidade Federal da Bahia, Salvador, BA, Brasil.

Douglas Bezerra Moraes - douglasmoraes_86@hotmail.com

Universidade Federal do Piauí, Teresina, PI, Brasil.

Alex Marques Nascimento - alexbruno.fmn@gmail.com

Docente da Universidade Federal de Campina Grande, Centro de Desenvolvimento Sustentável do Semiárido, Campina Grande, PB, Brasil.

Artigo submetido no dia 06-10-2014 e aprovado em 13-10-2015.

DOI: http://dx.doi.org/10.12660/cgpc.v20n67.35143 
Abstract: The paper analyzes the process of diffusion in state public bureaucracies in the country and the managerial modernization movement of the administrative structure, considering the experience of the state of Piauí. Although administrative reforms have been tried in States, some local contexts "resisted" the implementation of administrative practices and institutional structures that would lead to managerial modernization processes in public management, as evidenced by the case of Piauí. The concept of isomorphism and the narrative method was used for the study. As a result it was found that the attempt at administrative reform in Piauí in 2003 was made possible because of the rearrangement of political forces in the state and the diffusion mechanisms of institutional change and the modernization of public administration that occurred in the states. However, as the variation in institutional structures is influenced by local contexts, the results of the implementation of administrative reform in Piauí in 2003, various reforms were occurring in most Brazilian states.

Keywords: Management Reforms. Administrative Reform of Piauí. Isomorphism.

Resumen: El artículo analiza el proceso de difusión de las burocracias públicas estatales en el país y el movimiento de modernización de la gestión de la estructura administrativa que tenga para la experiencia del estado de Piauí. Aunque las reformas administrativas han sido analizadas en los estados brasileños, algunos contextos locales "resistieron"la aplicación de las prácticas administrativas y las estructuras institucionales que conducen a procesos de modernización de la gestión de la administración pública como se evidencia en el caso de Piauí. Este fue utilizado para estudiar el concepto de isomorfismo, y el método de la narración. Como resultado se encontró que el intento de reforma administrativa en Piauí en 2003, se ha hecho posible gracias a la reorganización de las fuerzas politicas en el estado y los mecanismos de difusión del cambio institucional y la modernización de la administración pública que se produjo en los estados. Sin embargo, como la variación en las estructuras institucionales se ven influidas por los contextos locales, los resultados de la aplicación de la reforma administrativa en Piauí en 2003, contienen diversas reformas que estaban ocurriendo en la mayoría de los estados brasileños.

Palabras clave: Reformas de gestión. Reforma Administrativa de Piauí. Isomorfismo

\section{INTRODUÇÃO}

Este estudo analisa o processo de difusão do gerencialismo no âmbito das burocracias públicas estaduais do país e do movimento de modernização da estrutura administrativa, que foi iniciado na segunda metade da década de 1990 e se estendeu ao longo da primeira década do século $\mathrm{XXI}$, tendo como caso para análise a experiência do estado do Piauí.

Nesse período, o Brasil passou por mudanças importantes no modo de concepção da gestão pública, em que se nota a difusão de mudanças gerencialistas nas reformas administrativas observadas nos governos estaduais. Entretanto, ainda que as reformas administrativas tenham sido pretendidas nos estados, alguns contextos locais revelam extrema dificuldade de implementação de práticas administrativas e deficiência nas estruturas institucionais necessárias para processos de modernização gerencialista da gestão pública.

Isso se deve ao contexto político e econômico de muita resistência devido à cultura patrimonialista no exercício do poder estadual, aliado à escassez de quadros administrativos capazes de implementar reformas ou processos de modernização na gestão.

Como considera Figueiredo (2001), em alguns casos, as reformas administrativas de cunho gerencialista dos estados tratavam apenas de reformas burocráticas. No caso do Piauí, isso é emblemático, pois, com seu contexto político-social desfavorável aos core values do gerencialismo, a implementação da reforma administrativa no estado a partir de 2003 foi prejudicada. Por esse motivo, a reforma administrativa piauiense foi, em parte, diferente das ocorridas nos outros esta- 
dos brasileiros, e até mesmo naqueles da própria região do Nordeste.

Para desenvolver a análise, foram utilizados o conceito de isomorfismo - oriundo da Teoria Institucional Sociológica - e o método das narrativas para identificar os elementos que caracterizaram a conjuntura em que se deu a mudança nos padrões de comportamento dos atores responsáveis pela gestão pública nos estados, bem como os mecanismos que possibilitaram a absorção das estruturas públicas estaduais e do discurso reformador introduzido no Brasil a partir de 1995, com a criação do Ministério da Administração e Reforma do Estado (MARE).

Após isso, procede-se à observação de como se deu o caso da reforma administrativa do estado do Piauí no contexto isomórfico de reformas administrativas estaduais. O artigo está estruturado em cinco seções. Esta introdução é a primeira. A segunda aborda a difusão da reforma gerencial no mundo e no Brasil; terceira trata o conceito de isomorfismo e analisa como se deu a difusão isomórfica das reformas administrativas de cunho gerencialista nos estados brasileiros; quarta versa sobre o método das narrativas, pois se trata de um estudo histórico. A quinta traz um dos casos de reformas administrativas inspiradas no gerencialismo, ocorrido no estado do Piauí. Buscamos, nessa seção, mostrar as desventuras da reforma e, ao mesmo tempo, mostrar os elementos isomórficos que a estimularam. As considerações finais encerram este estudo.

\section{A DIFUSÃO DAS REFORMAS GE- RENCIAIS NO MUNDO E O CASO BRASI- LEIRO}

As reformas administrativas gerenciais tiveram ampla difusão em todo o mundo. Surgem no bojo das reformas econômicas dos estados nos anos de 1980, constituindo-se a partir de então um movimento internacional de modernização da administração pública, denominado gerencialismo.

Contudo, a intitulada "reforma gerencial" variou de acordo com o contexto político-institucional no qual foi implementada devido aos sistemas político-administrativos e culturas administrativas próprias de cada estado-nação. Esse fato constitui um dos principais obstáculos enfrentados na avaliação dos diferentes desfechos da reforma nos países nos quais fora implementada, em razão de diversos fatores, como o problema da significação, a escassez de dados essenciais, a diversidade de critérios de análise e a dificuldade de ponderar a mudança (Pollitt \& Bouckaert, 2002; Hood, 1995; Bresser-Pereira, 1998).

Ao analisar as experiências internacionais, Bresser-Pereira (1998) aponta diferenças importantes na modernização das estruturas estatais de diferentes países. O caso da Grã-Bretanha é o mais equilibrado e bem-sucedido, com a reformulação profunda da administração pública britânica por meio da reestruturação de departamentos com o desenvolvimento de sistemas de informações gerenciais, o controle orçamentário pautado nos centros de custos, a profissionalização do serviço público, a flexibilização institucional por meio da contratualização, entre outras medidas.

Apesar das diferenças e de um início letárgi$\mathrm{co}$, o processo reformador nos Estados Unidos atinge resultados substanciais a partir 
de 1993 com o National Performance Reveiw, o pacote reformador lançado pelo presidente Bill Clinton. O objetivo era reinventar o estado, fazendo com que, por exemplo, os servidores deixassem o seu velho papel burocrático para tornarem-se empresariais, focando no controle de resultados e na competição em "quase-mercados." Como principais dificuldades encontradas no caso norte-americano, apresentam-se o caráter federativo do estado e a resistência de uma parte da burocracia bem instalada (Bresser-Pereira, 1998).

Ainda segundo Bresser Pereira (1998), na França, o processo de modernização é iniciado em 1989 e abandonado em seguida, sem a implementação de grandes mudanças institucionais, dedicando mais atenção para a dimensão da gestão e alcançando resultados gerenciais parciais, sem reforma institucional nem mudança das leis. Já o Japão, devido à sua conjuntura política, não optou pela descentralização, priorizando a criação de agências reguladoras, deixando de ser possível perceber mudanças significativas em sua estrutura estatal a partir do surgimento desse movimento internacional. Silberman (1993) apud Bresser-Pereira (1998) explica que essas discrepâncias se devem ao grau de burocratização das estruturas administras dos estados. O autor sugere que os países que apresentam estrutura estatal mais flexível têm maior capacidade de absorver os elementos que caracterizam as reformas gerenciais, como é o caso dos Estados Unidos e da Grã-Bretanha.

A reforma gerencialista no Brasil se dá efetivamente a partir de 1995, com a criação do Ministério da Administração e Reforma do Estado (MARE). A ideia conceitual mais im- portante da "Reforma Bresser" (como ficou conhecida a reforma gerencial no Brasil) foi a divisão do aparelho do estado em quatro setores: núcleo estratégico, atividades exclusivas, serviços não exclusivos e produção de bens e serviços para o mercado.

Fundamentalmente, a distinção desses setores no aparelho estatal possibilitaria ao governo privatizar ou conceder ao terceiro setor algumas das atividades centralizadas no estado, tais como: atividades produtivas, atividades de pesquisa, museus, ensino superior, hospitais e orquestras sinfônicas. (MARE, 1995).

Dessa maneira, pode-se afirmar que a reforma administrativa do MARE teve como elementos importantes, entre outros, a introdução do debate acerca da administração pública brasileira com visão empreendedora, num modelo fundado no controle dos resultados, em que o Estado passa a assumir apenas o papel de regulador, e não mais de produtor de serviços "quase-mercado" como telefonia e eletrificação - agora disponibilizados pela iniciativa privada.

No Brasil, o processo de difusão para os estados desse novo modo de gerir a coisa pública se aprofundou a partir dos anos de 2000. Isso porque o movimento de reforma administrativa brasileiro concentrou-se no âmbito federal, discutindo apenas superficialmente as questões dos entes federados sub-nacionais (MARE, 1995).

Um dos fatores que contribuíram para o retardo desse movimento foi o baixo grau de coordenação federativa. Outro elemento também muito importante foi a orientação básica constante no bojo conceitual da Nova Ges- 
tão Pública, segundo a qual seria impossível reinventar o governo de baixo para cima, devido ao seu tamanho, sendo aconselhável que a reforma fosse implementada em nível federal, acreditando-se que seria irradiada naturalmente para os estados (seguindo o modelo top-down).

Abrucio e Gaetani (2006) apontam dois fatos fundamentais para que os governos estaduais percebessem a necessidade da reforma administrativa. $O$ primeiro deles foi o processo de redemocratização do país ocorrido em 1988. Em decorrência do importante papel assumido pelos governadores na luta contra a ditadura militar no Brasil, os estados passam a ocupar melhor localização na estrutura federativa nacional, com mais poder e autonomia.

Essa descentralização ocorreu, principalmente, em razão de fatores: (1) transferência de competências (anteriormente centralizadas na esfera federal), para os entes sub-nacionais, passando a ser de responsabilidade conjunta das três esferas de governo; (2) consequente descentralização tributária e fiscal estabelecida na Constituição de 1988. Essa transferência de competências gerou um gigantesco descontrole das finanças públicas, intitulado "federalismo estadualista" (Sano, 2008, \& Abrucio, 1999).

Outro elemento que possibilitou a apropriação do discurso reformador pelos estados, segundo Sano (2008), Abrucio (1999) e Abrucio e Gaetani (2006), foi a implementação da moeda "Real" (esse período passou a ser denominado pelos autores de "era do Real"), em razão, primeiro, da bancarrota dos bancos estaduais influenciada pela elevação da taxa de juros e pelo fim do jogo in- flacionário, com a consequente privatização das instituições financeiras estaduais.

Segundo, em decorrência da política de centralização tributária, que aumentou os recursos disponíveis à União sem que eles tivessem de ser repassados aos governos estaduais. Exemplo: a criação da IPMF, posteriormente CPMF) e do Fundo Social de Emergência (FSE), retendo $20 \%$ dos recursos referentes ao Fundo de Participação dos governos estaduais na União (Sano, 2008).

Segundo Abrucio (1999), um dos fatores que caracterizou a crise fiscal dos estados gerada pelo Plano Real foi o excessivo gasto com pessoal. Em comparação ao PIB, a média de gastos com pessoal ativo da União era $3,4 \%$ de $1970-79$ e $2,9 \%$ de $1980-87$, com ligeira elevação no período de 1988-94. Enquanto nos governos sub-nacionais esses índices eram crescentes: $3,9 \%$ do PIB em 1970-79; 4,2\% em 1980-87, chegando a $6,5 \%$ em 1988-1994.

Outra característica também importante desse período foi o alto grau de endividamento dos estados e a posterior transferência deste para o Governo Federal. Segundo Abrucio (1999), no período de 1993-95, as dívidas vinculadas aos bancos estaduais quadruplicaram; as dívidas globais tiveram uma exorbitante elevação, de $R$ \$ 18 bilhões para $\mathrm{R} \$ 97$ bilhões no mesmo período.

Assim, estavam dadas as condições que conduziram os estados a introduzir o discurso modernizador nas agendas políticas. Motivados pela necessidade de equilibrar as contas públicas devido à perda de poder político, causada pelo cenário administrativo-econômico, os governos estaduais tiveram 
de redefinir seus padrões de comportamento, inserindo nas administrações públicas estaduais uma nova forma de atuar, modernizando-as, para recuperar o poder político perdido nos períodos anteriores.

\section{ISOMORFISMO E DIFUSÃO ISO- MÓRFICA DOS FUNDAMENTOS GEREN- CIALISTAS NAS REFORMAS ADMINIS- TRATIVAS NOS ESTADOS BRASILEIROS}

No que se refere às categorias de análise utilizadas para o desenvolvimento desta investigação, é possível, por meio do isomorfismo institucional, entender a difusão das reformas administrativas pelos estados e seu impacto no Piauí, isso porque esse conceito traz em seu bojo a preocupação com as mudanças das estruturas organizacionais em um dado campo organizacional, considerando, para isso, variáveis ambientais, como incerteza, legitimidade e dependência.

Uma das grandes contribuições da Teoria Institucional Sociológica foi enfatizar a importância da variável ambiental, analisando legitimidade e isomorfismo como elementos que contribuem para a mudança e sobrevivência das organizações. $O$ processo isomórfico se apresenta como um conjunto de forças que tornam as estruturas organizacionais de um dado campo organizacional homogêneo (Crubellate, 2007).

Dimaggio e Powell (1983) identificaram três mecanismos por meio dos quais ocorre a mudança isomórfica institucional, que são utilizados como estrutura categórica analítica desta pesquisa. O primeiro deles, isomorfismo coercitivo, é resultado da dependência e das expectativas culturais que determinadas organizações exercem sobre outras, isto é, são forças formais e informais que algumas organizações exercem sobre outras, influenciando suas estruturas organizacionais. Essa pressão pode ser observada de diversas formas: força, persuasão, convite para associar-se ou formas mais sutis.

Segundo Meyer e Rowan (1977), à medida que o estado e outras grandes organizações racionalizadas se expandem, aumenta a influência de regras institucionalizadas e legitimadas sobre as estruturas organizacionais, o que permite transparecer que a homogeneização de um dado campo organizacional está intimamente relacionada com as relações de autoridade.

O segundo mecanismo de mudança isomórfica institucional é isomorfismo mimético. Caracteriza-se como processo de mudança institucional no qual as organizações se espelham em outras devido ao grau de incerteza simbólica ambiental e a incompreensões tecnológicas. As organizações utilizam-se da modelagem (técnica que consiste em implantar modelos bem-sucedidos em outras organizações) para lidar com essas situações. Esses modelos podem ser difundidos de modo não intencional, de modo indireto ou de forma explícita (Dimaggio \& Powell, 1983).

O último mecanismo de mudança isomórfica institucional refere-se às pressões normativas, que provêm da ideia de profissionalização. Dimaggio e Powell (1983, p. 125) interpretam isso "como uma luta coletiva dos membros de uma ocupação para definir as condições e os métodos de seu trabalho, para controlar a 'produção dos produtores' e para estabelecer uma base e legitimação 
cognitivas para sua autonomia ocupacional".

De acordo com Machado-da-Silva, Fonseca e Crubellate (2005), o peso específico desses mecanismos dependerá do contexto de cada sociedade. Sugerem, por exemplo, que os mecanismos miméticos e normativos são mais facilmente encontrados em sociedades com forte tradição democrática e com alto nível de competição na oferta de bens e serviços, e os coercitivos têm especial destaque em sociedades de forte tradição patrimonialista, como é o caso do Brasil.

Essa perspectiva analítica apresenta, portanto, três mecanismos difusores dos conceitos gerenciais para as burocracias dos estados: isomorfismo coercitivo, que está relacionado à força das normas; isomorfismo mimético, que se apresenta diante das incertezas; isomorfismo normativo, pela profissionalização dos campos organizacionais. Esses conceitos aplicados à conjuntura de difusão de reformas administrativas brasileiras, que serão apresentados a seguir, vão ser indicados na narrativa Reforma do Piauí (seção 5 deste artigo).

Os elementos isomórficos coercitivos que atuaram na difusão da agenda reformadora gerencialista para os estados foram: Lei n. 9.496/97, Lei de Responsabilidade Fiscal (LRF), Lei de Diretrizes Orçamentárias (LDO), Lei Orçamentária Anual (LOA), Plano Plurianual (PPA), Programa de Modernização das Administrações Fiscais dos Estados Brasileiros (Pnafe), Programa Nacional de Apoio à Modernização da Gestão e do Planejamento dos Estados Brasileiros e do Distrito Federal (Pnage) e Programa de Modernização do Controle Externo dos Estados e Municípios Brasileiros (Promoex).
Por meio desse primeiro grupo de normas, o governo federal obrigava os estados a intensificar o controle das despesas, estimulava práticas que possibilitassem aumento da arrecadação dos estados pela limitação dos níveis de endividamento e incentivava também a profissionalização do planejamento público, com a utilização de instrumentos como LDO, LOA e PPA. Com isso, o governo federal estimulava as burocracias públicas estatais a buscar soluções inovadoras e inteligentes.

Apesar de o segundo grupo de ferramentas não ter o mesmo caráter punitivo que o primeiro, também foi de fundamental importância para a transferência do discurso gerencial para os estados. Devido à necessidade de adequar suas estruturas aos limites impostos pelo primeiro grupo de normas, os estados se viram obrigados a reestruturar suas burocracias e buscar nos programas nacionais, para esse fim, recursos e ideias para adaptarem suas estruturas.

Quanto aos elementos isomórficos miméticos, destaca-se a difusão de ações empreendedoras entre os Estados, devido ao fortalecimento das articulações entre eles, bem como à utilização de modelos bem-sucedidos em outros estados. No caso dos estados brasileiros, esse mecanismo foi fortemente utilizado em razão da não compreensão por parte de alguns governos estaduais do novo modelo de gestão que se tentava implementar no Brasil ou da baixa capacitação do corpo de servidores da maioria dos estados, o que gerava certa incompreensão sobre as novas tecnologias que seriam implementadas. 
Já os elementos isomórficos normativos podem ser percebidos a partir da migração de técnicos para os estados com a dissolução do MARE, da busca pela profissionalização da carreira de gestor público e da participação dos gestores estaduais em fóruns e nos conselhos estaduais.

A profissionalização é posta aqui como uma das principais pautas da agenda nacional da reforma administrativa. A ênfase na capacitação do corpo administrativo das burocracias estaduais coloca-se, por exemplo, como uma das principais práticas isomórficas normativas aplicadas na administração pública dos estados.

A reforma gerencial nos estados brasileiros é classificada por Araújo (2010) em três categorias: a) estados com maior número de inovações gerenciais, que procuram disseminar os avanços para as demais áreas; b) estados com número moderado de inovações gerenciais, que, apesar de implementarem grande número de experiências inovadoras, não conseguem disseminá-las; c) aqueles com reduzido número de iniciativas gerenciais, caracterizados por reformas pontuais sem nenhuma integração.

Na primeira categoria, a autora inclui os estados de Minas Gerais, Espírito Santo, Pernambuco, Bahia, Ceará e São Paulo. Segundo ela, esses estados tratam a melhoria da gestão como pauta transversal em suas agendas políticas, pois as ações abrangem várias áreas, e que, além de estarem conseguindo atingir bons resultados, obtêm certo grau de integração entre as diversas políticas. Contudo, apesar de existirem algumas iniciativas que buscam certa aproximação entre o cidadão e as administrações públi- cas, este ainda se configura como ator ausente no processo de formulação, implementação e avaliação das políticas públicas.

Como estados com grau moderado de inovações gerenciais, a autora classificou Paraná, Rio Grande do Norte, Moto Grosso, Rio Grande do Sul e Rio de Janeiro. Segundo Araújo (2010), apesar de terem obtido sucesso na implementação de iniciativas buscando a melhoria da gestão pública, como controle de gastos capacitação de servidores, profissionalização das compras, adoção de soluções de TI, elas são pontuais e não estão articuladas.

Já os estados com reduzido grau de inovações gerenciais, segundo a autora, sã: Roraima, Alagoas, Piauí, Santa Catarina, Tocantins, Maranhão e Amapá. Ela assim os classifica, pois em todos eles existem apenas iniciativas isoladas de melhoria da gestão pública, voltadas para o controle de gastos, possuindo como único registro de atividade direcionada para o atendimento ao cidadão, tal como as Centrais de Atendimento aos Cidadãos.

\section{MÉTODO DAS NARRATIVAS COMO RECURSO METODOLÓGICOS}

Nesta pesquisa, utilizou-se uma estrutura metodológica composta por dois eixos centrais: método das narrativas e conceito de isomorfismo neoinstitucional. O primeiro contribuiu para a sistematização lógica e contextualizada dos fatos que compõem o fenômeno em questão. Já o segundo constituiu a estrutura categórica analítica da pesquisa.

Partindo dessa escolha metodológica, é pos- 
sível compreender os eventos que caracterizaram a conjuntura de difusão de reformas administrativas nos estados brasileiros $\mathrm{e}$ como isso influenciou e impactou na reforma administrativa do Piauí. Evidencia-se como o contexto local da reforma do estado piauiense mostra a heterogeneidade na reforma gerencial dos estados.

O método das narrativas é histórico, que se propõe a aproximar-se da realidade social e de suas características processuais vinculadas à ação, o que possibilita organizar 0 fluxo de eventos observados em razão do sentido global atribuído ao fenômeno em estudo, prestando-se a apreender a realidade social como processo (Barzelay; Cortazar-Velarde, 2004; Fernandes, 2010).

O método narrativo busca explicar o fluxo lógico dos acontecimentos em seu contexto, a partir de uma abordagem qualitativa dos mecanismos causais, que constituem o processo de formulação e mudanças de fenômenos (Göttems, 2010; Barzelay; Cortazar-Velarde, 2004).

O resultado da aplicação do método narrativo é o relato, definido como "uma forma de representar uma experiência que conecta os acontecimentos em função do efeito que exercem sobre a experiência global" (Barzelay \& Cortazar-Velarde, 2004, pp. 23-24). O relato é composto por dois elementos básicos: os "eventos" e a "trama".

Barzelay e Cortazar-Velarde (2004, pp. 2324) apontam os eventos como elementos básicos na análise por meio da narrativa e o definem como "acontecimentos ou ações singulares que concorrem para dar forma a um aspecto ou parte da experiência to- tal em estudo". Fernandes (2010, pp. 23-25) os conceitua como "conjuntos de ações ou ocorrências organizadas em função de seu significado no âmbito de uma experiência apreendida em sua totalidade".

A "trama" é o argumento organizador do relato, que identifica o significado e o papel dos eventos em si. Assim, a trama constitui-se também de uma construção conceitual do pesquisador, reflexo de suas inquietações e do referencial teórico adotado na pesquisa "exerce uma função similar à das hipóteses da pesquisa analítica ao 'explicar' a experiência por meio de uma organização ou inteligibilidade dos eventos que dá sentido ao resultado ou desfecho" (Fernandes, 2010, p. 24).

A narrativa permite ao pesquisador: a) formular os distintos tipos de evento que compõem a experiência em estudo; b) estabelecer relações significativas entre os eventos, a partir da trama geral do relato; c) gerar perguntas de investigações relevantes (Barzelay \& Cortazar-Velarde, 2004).

Neste estudo, será usada a narrativa analítica como meio de descrição histórica dos eventos da reforma administrativa do Piauí, que podem ser caracterizados como isomórficos na tipologia conceitual de isomorfismo descrita na seção anterior.

\section{REFORMA ADMINISTRATIVA DO ESTADO DO PIAUÍ}

O Piauí é um estado que ainda conserva traços culturais e características econômicas do século XVII, como o cunho extrativista da economia (Mendes, 2003). Segundo relatório 2001-2002 do BIRD, entregue à fundação 
Cepro, o clientelismo e o apadrinhamento político são os principais entraves que atrasam e aumentam a miséria no Piauí.

Nesse cenário de marcas patrimonialistas e paternalistas, desenvolveu-se um aparato estatal com limitações diversas. Por meio do diagnóstico estadual - Piauí -, feito pelo Instituto de Pesquisa Econômica Aplicada (Ipea), realizado com o intuito de completar a pesquisa referente ao projeto denominado: "Programa de Apoio à Modernização da Gestão e do Planejamento dos Estados e do Distrito Federal" (Pnage), o qual consistiu em um diagnóstico geral das administrações públicas estaduais, realizado em 2003.

Pode-se perceber o quanto a estrutura físico-administrativa dos órgãos públicos do Piauí estava desajustada. Assim, constatou-se, nesse estado, que o quadro de pessoal estava "inchado", desqualificado e desmotivado. Além disso, comprometia mais de 50\% das receitas do estado, o que impossibilitava sua atuação quanto à implementação de políticas públicas (Piauí, 2003).

O grau de defasagem do quadro de pessoal da Administração Pública era tamanho que, desde a década de 1990, não eram realizados concursos públicos para a maioria dos órgãos do estado. Nos casos mais graves, essa realidade podia ser percebida desde os anos de 1980, segundo Relatório de Atividades (Piauí, 2003).

No ano de 2000, segundo o Ipea (2004), as despesas com pessoal e encargos no Piauí chegaram a $57,79 \%$ da receita corrente líquida do estado. O Piauí possuía 20,6 funcionários públicos estaduais para cada mil habitantes, o que estava acima da média do
Nordeste, que era de 18,7 funcionários/mil habitantes. No ano 2000, as despesas com inativos e pensionistas eram mais que o dobro das receitas de contribuição dos ativos (Ipea, 2004).

A reestruturação da burocracia pública foi um dos principais focos da reforma administrava implementada no início do governo Wellington Dias, pois a desorganização administrativa representava um dos principais obstáculos para a implementação de sua agenda política, isso porque, além do alto custo dessa estrutura (em dezembro de 2003, o estado do Piauí gastou aproximadamente $63 \%$ das receitas com pagamento de pessoal), o mau funcionamento da máquina pública estatal se agravava com a falta de conhecimento da equipe de governo a respeito da estrutura do estado.

Uma das principais dificuldades encontradas pela equipe de governo nos primeiros dias da nova gestão foi definir a quantidade de servidores. A desorganização era tamanha que, apesar de em novembro de 2002 o jornal O DIA ter publicado que o estado do Piauí apresentava algo em torno de 11 mil cargos ilegais, em janeiro de 2003, o governo eleito ainda não sabia ao certo quantos funcionários irregulares estavam naquele momento nos órgãos estaduais (Sena, 2003a).

O aparelho estatal piauiense constituiu-se historicamente de um módulo de sobrevivência das elites locais, servindo como fonte de prestígio e poder político e de gestão patrimonialista demonstrada em altos salários dos níveis de secretaria. A falta de controle sobre as contas do estado abrira indícios e denúncias de fraudes sobre documentos fal- 
sificados e corrupção publicadas na imprensa local.

Assim, a situação tanto financeira quanto administrava do estado do Piauí era de extrema desorganização e desequilíbrio das contas públicas. Dívidas como a das Águas e Esgotos do Piauí S/A (Agespisa), que em janeiro de 2003 estava na casa de $R \$ 270$ milhões, e a do Serviço Social do Estado (Serse), que chegou próximo de colocar o Piauí na lista do Cadastro Informativo de Créditos não Quitados do Setor Público Federal (Cadin), dificultaram a consecução de recursos fora do estado (Mendes, 2003).

Como consequência da dívida do estado em 2002, Hugo Napoleão, até então governador do Piauí, foi interpelado pela justiça por crime de responsabilidade fiscal juntamente com mais seis governadores de estados brasileiros (MG, RJ, MS, RS, ES e DF). A dívida desses estados com União chegava à quantia de $R \$ 250$ bilhões. Ou seja, antes de ser iniciada a reforma administrativa, a máquina pública estava desorganizada, desestruturada e repleta de problemas como se pode perceber na tabela a seguir construída a partir de relatório do Ipea (2004), conforme Quadro 1.

A maioria dos órgãos estava em condições precárias de funcionamento, com contas de água, luz e telefone atrasadas e com dificuldades de operar equipamentos de informática e de transportes e, também, abundância de problemas de estrutura física dos prédios públicos (Piauí, 2003).

Em virtude disso, além de ter de lidar com os salários atrasados herdados da gestão anterior, no ano 2003, Welington Dias afirmou que não haveria reajuste salarial por um ano em razão da péssima situação financeira do estado. Segundo ele, o estado tinha uma receita líquida mensal de aproximadamente $R$ \$ 110 milhões, dos quais $R \$ 107$ milhões cobriam folha salarial, aposentados e pensionistas ou quitação da dívida pública. Afirmou também que a situação só não era pior porque a Sefaz havia aumentado em 18\% sua arrecadação (Ipea, 2004).

A situação de fragilidade financeira do aparelho público piauiense justificava uma reforma administrativa que tivesse como objetivo central racionalizar o aparelho burocrático. O problema surgido foram as dificuldades encontradas devido às carências de um mínimo de burocracia pública capaz de implementar a reforma desejada.

\subsection{TENTATIVA "ISOMÓRFICA" GEREN- CIALISTA DE REFORMA ADMINISTRATI- VA NO PIAUÍ}

Tão importante quanto levantar os pontos que possibilitam compreender o contexto em que se deu a vitória petista no Piauí e a implementação da reforma administrativa, é conhecer como se deu esse processo.

Vale destacar que, assim como não se pode analisar a modernização da estrutura pública piauiense deslocada do contexto nacional e internacional, da mesma forma não é possível visualizar o momento referente à reestruturação administrativa no início do governo Wellington Dias isoladamente. Daí o esforço deste estudo para analisar, com base no isomorfismo, como se dá a reforma administrativa do Piauí (2003-2007).

É um processo que se inicia nessa ocasião, 
mas que se estende durante os dois mandatos do PT no estado do Piauí, em que se percebem indícios de continuidade no governo Wilson Martins (PSB), que iniciou sua gestão no ano de 2010. Porém se faz necessário um estudo mais aprofundado sobre a institucionalização do novo modelo de gestão iniciado no governo Dias.

Convém pontuar que esta pesquisa se propõe a compreender especificamente os elementos que possibilitaram a emersão da modernização da estrutura administrativa do estado do Piauí em 2003, não interessando a compreensão dos elementos que influenciaram o processo de implementação dessa política após esse ano. Isso porque, como será visualizado mais adiante, no decorrer dos dois mandatos petistas, muitas alterações foram feitas na proposta inicial da reforma, até mesmo sob influência das pressões institucionais do campo organizacional no qual estava inserido o Piauí, de forma que esse fenômeno especificamente merece um estudo aprofundado.

Mecanismos de ocorrência da mudança isofórmica institucional

\section{a) Isomorfismo coercitivo}

Influenciados pela LRF e pelo Pnage, o isomorfismo coercitivo na tentativa de reforma no Piauí tem como sua principal ferramenta de implementação a lei complementar n. 28, de junho de 2003.

Essa norma dispõe sobre a Lei Orgânica da Administração Pública do Estado do Piauí e dá outras providências (Piauí, 2003). Sua principal contribuição foi a definição da quantidade exata de cargos existentes em cada secretaria do estado, pois, como apresentado anteriormente, a última tentativa de organizar sua estrutura administrativa ocorreu em 1991, no governo de Freitas Neto, e até 2003 era desconhecida até mesmo a quantidade de funcionários públicos do estado.

Essa lei também trouxe outras contribuições no que se refere à estrutura administrativa do estado. A principal mudança implementada foi a criação das ouvidorias e das controladorias do estado, que proporcionaram maior controle sobre a gestão da "coisa pública". Cria também duas novas unidades organizacionais dentro do estado: coordenadorias e superintendências, que visavam dar agilidade à ação estatal (Piauí, 2003).

Apesar de se perceber nesta proposta algumas ideias e conceitos já característicos de um modelo gerencial de administração pública, tais como a flexibilização da gestão, eficiência, divisão entre níveis estratégicos e não estratégicos, predominou, nesse primeiro momento, a ênfase no controle e na legalização dos processos.

Assim, a modernização administrativa do estado do Piauí iniciada em 2003 trazia em seu bojo basicamente uma ideia de legalização e controle. Grosso modo, esse momento inicial da reforma pode ser facilmente entendido como "reforma burocrática" da administração pública piauiense.

Contudo, é importante frisar que o foco inicial na legalização e no controle dos processos não coloca a reforma administrativa piauiense de 2003 em um patamar diferente das propostas implementadas nos demais estados e no governo federal, pois, como 
argumenta Abrucio (2007), perceber uma relação de oposição completa entre a chamada administração burocrática e as novas formas de gestão foi um dos principais erros da reforma Bresser. $\mathrm{O}$ autor argumenta que essa relação é um movimento dialético, com a incorporação de aspectos do modelo weberiano e a criação de novos instrumentos de gestão.

Apesar da lógica de legalização e do controle em que estava inserida a gestão de Wellington Dias no início da reforma terem se materializado basicamente na lei complementar n. 28, ela influenciou toda a estrutura administrativa direta e indireta do estado no início do governo. Fato esse que pode ser percebido analisando o objetivo de algumas das leis enviadas para a assembleia legislativa juntamente com a lei complementar n. 28, que assim como esta, resultaram de um estudo realizado pela equipe de governo e por uma empresa de consultoria da UnB, Finantec.

A equipe de governo se caracterizava nesse momento principalmente pela pouca experiência de governo e pelo pouco conhecimento sobre o funcionamento do estado, o que estimulava seus componentes a buscar soluções e inspirações em experiências que vinham sendo aplicadas em outros estados da federação.

As leis que implementaram a reforma não se detiveram na exposição clara de objetivos, de estratégias, da missão e de outras questões menos operacionais; focaram apenas em mudanças emergenciais, no que se refere ao ajuste das contas públicas do estado, enquanto as demais foram ocorrendo posteriormente, sem projeto que as estruturasse.

Para melhor entendimento da proposta reformadora implementada no Piauí, em 2003, faz-se necessário pontuar o contexto no qual se deu a aprovação da LC n. 28.

No início do governo, um dos principais obstáculos às novas orientações implementadas pelo governo do PT era atender aos interesses dos diversos agrupamentos que compuseram formal e informalmente a base de apoio da campanha eleitoral de Wellington Dias. Devido às diversas alianças construídas durante o processo eleitoral, a mudança dos padrões de relacionamento da classe política do Piauí com a "coisa pública" tornou-se lenta e dialogada, principalmente porque o resultado das urnas na eleição de governador não se repetiu na eleição dos deputados estaduais.

O PT fazia um governo de minoria, o que o forçava a dialogar com as demais forças dentro da Assembleia Legislativa do Estado (Alepi), para que pudesse ter boa governabilidade. Dessa forma, como boa parte da base aliada que possibilitou a eleição do governo do PT no estado era representante das elites locais que historicamente vinham construindo a burocracia estatal no Piauí, o governo Wellington Dias e suas propostas à Alepi tiveram forte oposição tanto de aliados quanto do grupo oposicionista no início do mandato.

Como observado em entrevista do então governador Wellington Dias ao jornal Meio Norte, cerca de $90 \%$ dos dados negativos sobre o início de seu governo eram provenientes da base aliada, que estava descontente com as medidas do novo governo, e 
apenas $10 \%$ oriundas da oposição (Ribeiro, 2004).

Assim, vendo-se obrigado a negociar com as demais forças políticas que compunham a Alepi naquele momento, o governo consegue aprovar a estrutura administrativa proposta incorporando algumas das alterações exigidas pelos demais grupos, com 23 votos a favor em primeiro turno e com 24 votos a favor em segundo turno. Isso, segundo o jornal O DIA, só foi possível em razão do acordo estabelecido entre oposição e governo (Sena, 2003b).

A relação entre o executivo e o legislativo durante o governo Dias foi muito negociada, o que viabilizou a aprovação da lei complementar n. 28 e do conjunto das demais reformas que tentavam implementar um novo modelo de gestão no estado do Piauí.

Como dito anteriormente, a reforma administrativa implementada no Piauí não pode ser percebida em sua totalidade no momento inicial do governo Wellington Dias, pois, no decorrer de seus dois mandatos, a lei complementar n. 28 sofreu alterações por meio de outras leis complementares que buscavam adequar a estrutura administrativa do estado aos novos conceitos que estavam sendo inseridos no estado, como, por exemplo, o modelo de Organizações Sociais (OSs) (Piauí, 2007).

Ao todo, até o fim do governo Wellington, foram aprovadas sete leis complementares que alteravam o conteúdo da lei complementar n. 28, buscando adequá-la aos novos conceitos que vinham sendo inseridos. Entre elas, as mais importantes foram as leis complementares n. 42/2004 e n. 83/2007.
A primeira objetiva corrigir algumas discrepâncias na LC n. 28/2003, pois, neste mesmo ano, o governo do estado aprovou o plano de carreira dos servidores estaduais (até esse período os servidores não tinham plano de carreira estruturado), o que, juntamente com a redução do repasse federal para os estados (FPE), o obrigou a enxugar a estrutura administrativa implementada em 2003, de forma que somente no segundo mandato foram recriados alguns dos elementos extintos por meio da LC n. 42.

A segunda, a lei complementar n. 83/2007, aprovada no segundo mandato de Wellington, sob forte influência dos conceitos trazidos pelo Pnafe, pelo Pnage e por meio do Consad, tentou avançar na agenda do modelo gerencial de administração pública. Esses programas trazem para o contexto piauiense conceitos e soluções que vinham sendo praticados em outros estados, como o modelo de OS, o modelo de gestão por resultados e a proposta do contrato de gestão.

\section{b) Isomorfismo mimético}

O isomorfismo mimético no Piauí ocorre no instante em que, com base em experiências de outros estados, como Minas Gerais e São Paulo, o governo cria, com a LC 83/2007, a Empresa de Gestão de Recursos do Piauí $\mathrm{S} / \mathrm{A}$ (Emgerpi). Essa estava vinculada à Secretaria de Administração do Estado, nos termos do art. 68 A, B, C e D, da Lei complementar n. 83, de 12 de abril de 2007, e tinha como finalidade prioritária capacitar, aperfeiçoar, absorver, redistribuir e ceder pessoal para órgãos e entidades da Administração Pública Estadual, objetivando otimizar a utilização e o gerenciamento de recursos humanos do Poder Público Estadual. Essa lei autorizou 
o poder executivo a transformar a Central de Abastecimento do Piauí S/A (Ceasa) na Emgerpi e repassar para Organizações Sociais a gestão das atividades da primeira.

Entre algumas das ações gerencialistas implantadas pela Emgerpi, com base em ações exitosas da reforma mineira, estavam: Programa de gestão por resultados, Programa de gestão de talentos e Reformulação e modernização administrativa (Emgerpi, 2008).

A criação da Emgerpi tinha como fundamento a gestão dos órgãos da administração indireta, que estavam em estado falimentar: I - Companhia de Desenvolvimento do Piauí (Comdepi); II - Águas e Esgotos do Piauí S/A (Agespisa); III - Empresa de Informática e Processamento de Dados do Estado do Piauí (Prodepi); IV - Companhia de Habitação do Piauí (Cohab); V - Companhia Editora do Piauí (Comepi). Desses, apenas a Agespisa ainda não foi anexada à Emgergi, estando todos os demais incorporados a ela, passando os quadros de pessoal e as transações pendentes a pertencer a essa empresa. Foi criada uma autarquia para exercer as atividades de cada um desses órgãos.

O principal objetivo dessa reestruturação era possibilitar que essas novas organizações realizassem transações diretamente com outras organizações, tendo em vista estarem sem nenhuma restrição no mercado.

Ao mesmo tempo em que a Emgerpi tinha o papel de gerir o espólio dos órgãos antes citados, também tinha forte preocupação com a eficiência, como se pode perceber analisando seu principal objetivo. Pautada nessa preocupação, essa empresa tentou introduzir, na estrutura dos órgãos que geria, a preocupação com a gestão por resultados e com a contratualização por meio do Programa Gestão para Resultados - PGR (Emgerpi, 2008).

Contudo, devido ao estado falimentar da estrutura pública piauiense e à autonomia da Emgerpi (o que Ihes permitia maior agilidade), ela assumiu outras funções, passando de gestora da massa falida do estado para agente catalisador de políticas públicas. Apesar dessa mudança se configurar apenas na prática e não nos seus documentos constitutivos, a Emgerpi assumiu uma posição de destaque no estado, no tocante à agilidade e à eficiência.

\section{c) Isomorfismo normativo}

Quanto ao isomorfismo normativo, a reforma administrativa do Piauí recebeu influência do Consad. As práticas discutidas nesse evento foram paulatinamente incorporadas nos discursos durante a implantação da reforma.

Além disso, destaca-se a criação da Escola de Governo do Piauí. Nela, técnicos do governo capacitaram-se e disseminaram experiências ao longo das diversas secretarias do governo. Some-se a isso o fato de o governo ter contratado uma empresa de consultoria da Universidade de Brasília, chamada Finantec, para contribuir para a capacitação dos agentes públicos e os conselheiros estaduais (Ipea, 2004).

\section{CONSIDERAÇÕES FINAIS}


A implementação de uma reforma administrativa pautada na agenda da New Public Manegement no estado do Piauí, em 2003, tornou-se possível devido ao rearranjo de suas forças políticas e aos mecanismos isomórficos de mudança institucional, que possibilitaram a absorção, por parte dele, do discurso reformador oriundo do movimento internacional de modernização das estruturas públicas iniciado nos anos de 1980.

Assim como nos demais estados brasileiros, marcado por práticas patrimonialistas e fisiologistas oriundas de seu processo de formação social marcadamente antidemocrático, a administração pública do Piauí caracterizava-se pelo não incentivo à participação popular na gestão da coisa pública, o que dificultava, ou até mesmo impossibilitava, reformar a estrutura administrativa do estado.

A eleição de Wellington Dias (PT) para o governo do Piauí apontava para uma mudança na maneira como o estado se relacionava com a sociedade, tanto pelas bandeiras históricas do PT, quanto pela necessidade de diferenciar as antigas gestões. Esse fato tornou possível reestruturação da máquina administrativa piauiense.

A reforma administrativa implementada no Piauí, em 2003, trouxe em seu bojo alguns conceitos presentes na proposta reformadora implementada no Brasil em 1995, isso devido à tendência homogeneizadora do sistema federativo brasileiro àquela época. O processo de formulação e implementação da reforma administrativa piauiense de 2003 sofreu forte influência dos três mecanismos isomórficos de mudança institucional, contudo, o isomorfismo normativo só passa a ter maior influência sobre esse processo após 2003, durante o processo de implementação da reforma, com a criação da Escola de Governo, dando maior ênfase à capacitação, e com a maior participação dos gestores estaduais nos fóruns e conselhos estaduais, disseminação dos debates no Consad e contratação da empresa de consultoria da UNB, Finantec.

O isomorfismo mimético ocorreu devido aos altos níveis de incerteza e da incompreensão de determinadas técnicas de gestão e até mesmo ao próprio desconhecimento sobre a real situação da máquina pública piauiense. A equipe do novo governo buscou ideias e soluções para resolver seus problemas analisando experiências bem-sucedidas de outros estados e contratando profissionais especializados na área. Como resultado disso, o governo cria a Emgerpi, que passa a reproduzir práticas e experiências exitosas em outros estados, ainda que com algumas falhas. O coercitivo teve grande influência sobre a introdução desses novos conceitos na proposta piauiense. A influência do isomorfismo coercitivo pode ser percebida no caso do Piauí, primeiro a partir da Lei de Responsabilidade Fiscal e do Pnafe, que contribuíram no momento inicial para a construção da proposta reformadora piauiense. O Pnage também influenciou, entretanto sua contribuição pode ser encontrada de maneira predominante somente durante o processo de implementação e reformulação.

No Piauí, o isomorfismo coercitivo pode ser observado por meio das legislações estaduais, como a LC, de 28 de junho de 2003. Com ela, a reforma estabeleceu obrigatoriedade de eficiência e enxugamento da máquina pública. Entretanto, a trama política local 
demonstra que, para implantar a reforma administrativa do Piauí, o governo enfrentou significativos entraves com o poder legislativo estadual. Aprovada a Lei n. 28, ele ainda precisou fazer ajustes na sequência.

Para finalizar, da mesma forma que a nível nacional, seria um erro falar em fim do legado no que se refere à modernização das estruturas públicas do estado do Piauí, pois, de modo similar aos demais estados, ainda há muito no que se avançar no sentido da implementação da agenda reformadora dos anos de 1980.

\section{REFERÊNCIAS}

Abbott, A. (2001).Times matters - on theory and method. Chicago: The University of Chicago Press.

Abrucio, F. (2007). Trajetória recente da gestão pública brasileira: um balanço crítico e a renovação da agenda de reformas. Rev. Adm. Pública. v. 41 (Edição Especial), pp. 67-86.

Abrucio, F. (1999). O longo caminho das reformas nos governos estaduais: Crises, mudanças e impasses. In.: MELO, Marcus André (org.). Reforma do Estado e Mudança Institucional no Brasil. Recife: Fundação Joaquim Nabuco, Editora: Massangana. $p$. 368.

Abrucio, F.; Gaetani, F. (2006). Avanços e perspectivas da gestão pública nos estados: agenda, aprendizado e coalizão. In: Consad. Avanços e perspectivas da gestão pública dos estados. Brasília: Consad.

Araújo, M. A. D. (2010). Novas formas alter- nativas de prestação de serviços. In: Conselho Nacional de Secretários de Estado da Administração. (Org.). Avanços e Perspectivas da Gestão Pública nos Estados II. pp. 107-138.

Barzelay, M, \& Cortazar-Velarde, J. C. (2004). Una guia práctica para la elaboración de estudios de caso sobre buenas prácticas en gerencia social. Washington: Banco Interamericano de Desarrollo - BID / Instituto Interamericano para EI Desarrollo Social - INDES.

Bresser Pereira, L. C. (1998). A reforma do Estado dos anos 90 - lógica e mecanismos de controle. Lua Nova. n. 45, pp. 49-95.

Corrêa, I. M. (2007, maio/jun.). Planejamento estratégico e gestão pública por resultados no processo de reforma administrativa do estado de Minas Gerais. Rio de Janeiro. Revista de administração Pública - RAP. 41(3):487-504.

Crubellate, J. M. (2007). Três contribuições conceituais neofuncionalistas à teoria institucional em organizações. RAC - Revista de Administração Contemporânea, v. 11, pp. 199-222.

Dimaggio, P., \& Powell, W. (1983). The iron cage revisited: institutional isomorphism and collective rationality in organizational fields. American sociological review 48: 147-60.

Empresa de Gestão de Recursos do Piauí S/A [EMGERPI]. (2008). Programa Gestão de Resultados. p. 11 (Digital), Teresina (Piauí).

Fernandes, A. S. A. (2010, set.). Conselhos 
municipais - participação, efetividade e institucionalização - a influência do contexto político na dinâmica dos conselhos. CADERNOS EBAPE. BR, v. 8, n. 3, artigo 4, Rio de Janeiro.

Figueiredo, A. C. (2001). Prefácio. In: SANTOS, Fabiano (Org.) O poder legislativo nos estados: diversidade e convergência. v. 34, p. 9-12. Rio de Janeiro: FGV.

Göttems, L. B. D. (2010). Análise da política de atenção primária à saúde desenvolvida no Distrito Federal: A articulação entre o contexto político, os problemas, as alternativas e os atores na formação da política de saúde (1979 a 2009). Tese de doutoramento, Programa de Pós-Graduação em Administração da Faculdade de Economia, Administração, Contabilidade e Ciências da Informação e Documentação, Universidade de Brasília, Brasília, DF.

Hall, P. A.; Taylor, R. C. R. (2003). As três versões do neoinstitucionalismo. Lua Nova [online]. n. 58, pp. 193-223.

Hood, Cristopher. (1995). The new public management in the 1980s: variation on a theme. Accounting Organizations and Society 20(3), p. 3-19, London (UK), Pergamon.

IPEA - Instituto de Pesquisa Econômica Aplicada. (2004). Diagnósticos Estaduais Piauí. Relatório de Pesquisa, Brasília, DF.

Machado-da-Silva, C. L., Fonseca, V. S. da, \& J. M. Crubellate (2005). Estrutura, agência e interpretação: elementos para uma abordagem recursiva do processo de institucionalização. RAC - Revista de Administração Contemporânea, pp. 9-39. (Edição Especial).
Meyer, J., \& Rowan, B. (1977). Institutionalized organizations: formal structure as myth and ceremony. American Journal of Sociology. v. 83. n. 2. pp. 340-363.

MARE (Ministério da Administração Federal e da Reforma do estado) (1995) Plano Diretor da Reforma do Aparelho do Estado. Brasília: Imprensa Nacional, Novembro.

Mendes, F. (2003). Economia e desenvolvimento do Piauí. Teresina: Fundação Cultural Monsenhor Chaves.

Piauí - Governo do Estado do Piauí. (2003). Secretaria de Estado da Educação e Cultura. Relatório de atividades - janeiro a juIho/2003, p. 8

Piauí - Governo do Estado do Piauí. (2007). Lei Complementar n. 83 de 12 de abril de 2007, Cria a Empresa de Gestão de Recursos do Piauí - Emgerpi.

Pollitt, C, \& Bouckaert, G. (2002). Avaliando reformas da gestão pública: uma perspectiva internacional. Revista do Serviço Público. Ano 53. Número 3. jul.-set. 2002.

Rezende, F. C. (2004). Por que falham as reformas administrativas? Rio de Janeiro: FGV. 2004.

Ribeiro, P. J. F. (2004). Um partido em mutação: A transformação do PT e seus reflexos sobre as campanhas presidenciais (1989, 2002). São Carlos: UFSCar. p. 184.

Sena, Y. (2003a). Governo do estado tem 11 mil cargos ilegais. Jornal O DIA. Piauí: Teresina. 15 fev. Política. p. 3. 
Sena, Y. (2003b) Oposição bem situada: O dono do pedaço. Jornal O DIA. Piauí: Teresina. 10,11 e 12 fev. Política. p. 4.
Sano, H. (2008). Articulação horizontal no federalismo brasileiro - os Conselhos de secretários estaduais, Tese de Doutorado da Fundação Getúlio Vargas.

\section{ESTRUTURA ADMINISTRATIVA}

- Ineficiência e ineficácia dos processos de gestão e inadequação das estruturas organizacionais, normativas e regulatórias da administração pública estadual

- Carência da gestão da memória administrativa

- Sobreposição de competências

- Deficiência na gestão de contratos e convênios

\section{RECURSOS HUMANOS}

- Precariedade do sistema de informação gerencial de RH

- Ausência de política de RH

- Baixa qualificação dos servidores

- Precariedade das informações relativas aos recursos humanos

\section{SISTEMA DE PLANEJAMENTO}

- Ausência de sistema de coleta e apuração de dados primários

- Desarticulação do sistema de planejamento

- Baixo nível de integração entre planejamento, orçamento e execução financeira

- Deficiência na gestão por programas e dificuldade de articulação com as metas

- Deficiência dos sistemas e instrumentos deacompanhamento, controle eavaliação das políticas públicas

- Descoordenação das ações de governo

\section{GESTÃO E POLÍTICAS PÚBLICAS}

- Ausência de sistemas de informação gerencial

- Fragilidade gerencial na execução das políticas

- Fragilidade na coordenação de políticas

- Dificuldade das secretarias de administração/planejamento em exercer seu papel estratégico

\section{TECNOLOGIA DE GESTÃO}

- Baixa informatização

- Baixa adoção de ferramentas de gestão

- Dificuldade na apropriação e avaliação de custos

- Baixa incidência de práticas de gestão voltadas para resultado

- Deficiência na gestão do patrimônio mobiliário e imobiliário

- Desconhecimento da cultura organizacional

- Falta de avaliação no processo de reforma administrativa (gestão)

Continua. 
Antônio Sérgio Araújo Fernandes - Douglas Bezerra Moraes - Alex Marques Nascimento

\begin{tabular}{|c|}
\hline NORMATIZAÇÃO E CONTROLE \\
\hline - Falta de atualização e consolidação da legislação e dificuldade para sua utilização gerencial \\
\hline - Frágil controle dos contenciosos judiciais \\
\hline - Fragilidade do sistema de controle interno \\
\hline - Sistemas de controle interno descolados do planejamento e da avaliação de resultados \\
\hline - Desarticulação entre os sistemas de controle interno e externo \\
\hline SISTEMAS DE INFORMAÇÃO \\
\hline - Ausência de dados básicos sobre gestão de tecnologias \\
\hline - Descoordenação das ações na gestão de TI \\
\hline - Má gestão da informação e da tecnologia da informação \\
\hline PRESTAÇÃO DE SERVIÇOS PÚBLICOS E ATENDIMENTO AO CIDADÃO \\
\hline - Ausência de política de prestação do serviço público \\
\hline - Ausência de política de avaliação sistemática na prestação do serviço público \\
\hline - Baixa transparência no atendimento ao cidadão \\
\hline REDES DEMOCRÁTICAS DE GOVERNANÇA \\
\hline - Falta de monitoramento da conduta ética e disseminação de valores éticos \\
\hline - Falta de efetividade na responsabilização dos servidores \\
\hline - Falta de diagnóstico das necessidades do usuário \\
\hline - Falta de transparência das ações administrativas \\
\hline - Ineficiência da prestação de contas governamentais \\
\hline - Fragilidade da política de comunicação com o servidor \\
\hline PROBLEMAS ESTRATÉGICOS \\
\hline - Ausência de sistemas de informações básicos, como bancos de dados atualizados \\
\hline - Baixa capacitação dos funcionários para as atividades básicas \\
\hline
\end{tabular}

QUADRO 1. Os principais problemas encontrados pelo IPEA (2004) no Piauí, em 2003. Fonte: Elaboração do autor 